\title{
Effect of Tween 40 and DtsR1 on L-arginine overproduction in Corynebacterium crenatum
}

\author{
Minliang Chen ${ }^{1,3}$, Xuelan Chen ${ }^{2 *}$, Fang Wan², Bin Zhang ${ }^{2}$, Jincong Chen ${ }^{1,3}$ and Yonghua Xiong1,3*
}

\begin{abstract}
Background: L-Glutamate is an important precursor in the L-arginine (L-Arg) biosynthetic pathway. Various methods, including polyoxyethylene sorbitan monopalmitate (Tween 40) addition and dtsR1 disruption, have been widely used to induce L-glutamate overproduction in Corynebacterium glutamicum. In this study, a novel strategy for L-Arg overproduction through Tween 40 trigger and $\Delta d t s R 1$ mutant were proposed in Corynebacterium crenatum.

Results: Corynebacterium crenatum mutant (CCM01) was selected as a host strain, whose argR was lethal via mutagenesis screening, the $p r o B$ gene was knocked out, and $\arg B$ was replaced by $\arg B$ M4 (E19R, H26E, D311R, and D312R) to release L-Arg feedback resistance. After Tween 40 trigger in the logarithmic period, L-Arg production increased from 15.22 to $17.73 \mathrm{~g} / \mathrm{L}$ in CCM01 strain. When NCg/1221 and dtsR1 disruption (CCM03), L-Arg production drastically increased to $27.45 \mathrm{~g} / \mathrm{L}$ and then further to $29.97 \mathrm{~g} / \mathrm{L}$ after Tween 40 trigger. Moreover, the specific activity of $\alpha$-oxoglutarate dehydrogenase complex (ODHC) decreased, whereas the regeneration of $\mathrm{NADP}^{+} / \mathrm{NADPH}$ significantly increased after dtsR1 disruption and Tween 40 trigger. Results of real-time PCR showed that the transcriptional levels of $O d h A, S U C B$, and IpdA (encoding three subunits of the ODHC complex) were downregulated after Tween 40 trigger or dtsR1 disruption. By contrast, zWf transcription (encoding glucose-6-phosphate dehydrogenase) showed no significant difference among CCM01, CCM02 ( $\Delta$ NCg/1221), and CCM03 ( $\Delta$ NCg/1221 $\Delta d t s R 1)$ strains without Tween 40 trigger but evidently increased by 5.50 folds after Tween 40 trigger.
\end{abstract}

Conclusion: A novel strategy for L-Arg overproduction by dtsR1 disruption and Tween 40 trigger in C. crenatum was reported. Tween 40 addition exhibited a bifunctional mechanism for L-Arg overproduction, including reduced ODHC activity and enhanced NADPH pools accumulation by downregulated $d t s R 1$ expression and upregulated zwf expression, respectively.

Keywords: Corynebacterium crenatum, L-Arginine, Tween 40, DtsR1, $\alpha$-Oxoglutarate dehydrogenase complex, $\mathrm{NADP}^{+} / \mathrm{NADPH}$

\section{Background}

$\mathrm{L}$-Arginine ( $\mathrm{L}$-Arg) is a semi-essential amino acid that is widely used as an additive in food, cosmetic, and pharmaceutical industries because of its ability to promote

\footnotetext{
*Correspondence: xuelanchen162@163.com; yhxiongchen@163.com

${ }^{2}$ Key Laboratory of Functional Small Organic Molecule, Ministry

of Education, Jiangxi Normal University, 99 Ziyang Road,

Nanchang 330022, People's Republic of China

${ }^{3}$ State Key Laboratory of Food Science and Technology, Jiangxi-OAI

Joint Research Institute, Nanchang University, 235 Nanjing East Road,

Nanchang 330047, People's Republic of China

Full list of author information is available at the end of the article
}

secretion of growth hormones [1], insulin [2], and prolactin [3] and facilitate the synthesis of various immune active factors to prevent cancer cell growth [4]; L-Arg is a nitric oxide precursor for relaxing and dilating blood vessels [5]. Different microorganisms, such as Corynebacterium glutamicum [6, 7], Escherichia coli [8], Bacillus subtilis [9], and Saccharomyces cerevisiae [10], are used as model organisms for L-Arg overproduction.

In recent decades, various strategies based on genetic engineering technology have been designed to improve industrial levels of L-Arg. Ginesy et al. [8] reported 
an engineered $E$. coli strain for L-Arg overproduction by deleting the $s p e C$, speF, $\operatorname{argA}$, adiA, and $\operatorname{argR}$ genes, introducing feedback-resistant $\arg A 214$, and overexpressing $\arg O$ genes, whose L-Arg final production was achieved at $11.64 \mathrm{~g} / \mathrm{L}$ in $1-\mathrm{L}$ batch fermentation. $\mathrm{Xu}$ et al. [11] also performed site-directed mutagenesis of $\mathrm{N}$-acetyl-L-glutamate kinase (including E19R, H26E, and H268D) to alleviate feedback inhibition by L-Arg; LArg production improved by about $41.7 \%$ as compared with that of the initial strain. Moreover, $\mathrm{Xu}$ et al. overexpressed L-Arg biosynthetic genes, including the $\operatorname{argC} \sim \mathrm{H}$ cluster [12] and the lysE gene [13] in Corynebacterium crenatum SYPA 5-5; L-Arg production was achieved at 45.3 and $35.9 \mathrm{~g} / \mathrm{L}$, respectively, by batch fermentation in a 5 -L bioreactor. Lee et al. [14, 15] reported a metabolically engineered C. glutamicum for production of L-Arg at the industrial-scale based on systems metabolic engineering, including random mutagenesis to release feedback inhibition, knocking out $\operatorname{argR}$ and farR genes to remove repressors, increasing NADPH and carbamoyl phosphate pools, and deleting NCgl1221 gene to avoid L-glutamate exporter. Subsequently, L-Arg production distinctly increased to $92.5 \mathrm{~g} / \mathrm{L}$ by fed-batch fermentation in a 5 - $\mathrm{L}$ bioreactor.

L-Glutamate is an important precursor in the L-Arg biosynthetic pathway. Previous research has demonstrated that reduced $\alpha$-oxoglutarate dehydrogenase complex (ODHC) activity can significantly induce L-glutamate overproduction in C. glutamicum by increasing metabolic fluxes toward L-glutamate synthesis (as shown in Fig. 1). As a fermentation trigger, polyoxyethylene sorbitan monopalmitate (Tween 40) is widely used to enhance L-glutamate overproduction in C. glutamicum because it can decrease ODHC activity by downregulation of $d t s R 1$ expression [16]. DtsR1 protein is a homolog of the subunit of the biotin enzyme acetyl-CoA carboxylase complex, and disruption of the $d t s R 1$ gene can notably reduce ODHC activity, leading to an increase in L-glutamate production $[17,18]$. However, to our knowledge, the strategy by adding Tween 40 and deleting $d t s R 1$ for L-Arg overproduction has not been published. C. crenatum is highly homologous to C. glutamicum and is frequently used for production of various amino acids, including L-Arg, because of its genetic tractability,

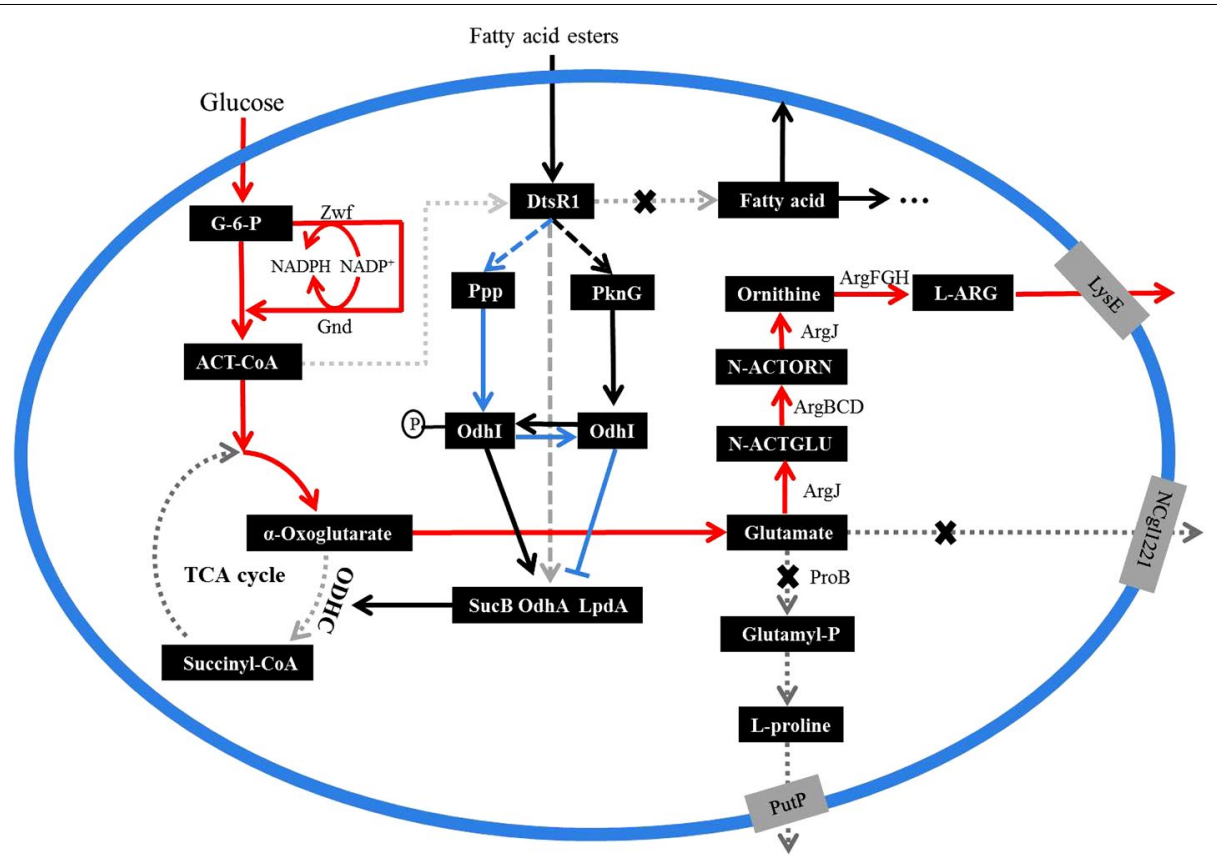

Fig. 1 Correlation biosynthetic pathway of L-Arg and possible signaling cascade involved in the regulation of ODHC specific activity under Tween 40 addition by C. crenatum (Brief). Red thick arrows indicate increased fluxes by overexpressing the corresponding genes. Dot-dashed lines represent decreased or cut off fluxes by reducing relevant enzyme activity and knocking out relevant genes, respectively. G-6-P glucose-6-phosphate, ACTCoA acetyl-CoA, Zwf glucose-6-phosphate dehydrogenase, Gnd 6-phosphogluconate dehydrogenase, ProB gamma-glutamyl kinase, PutP L-proline exporter, NCg/1221 glutamate exporter, LysE L-Arg and L-lysine exporter, N-ACTGLU N-acetylglutamate, N-ACTORN N-acetylornithine, arg JBCDF-argGH, the gene clusters of L-Arg biosynthetic pathway, DtsR1 acetyl-CoA carboxylase, AccBc biotin carboxylase and biotin carboxyl carrier protein, $P k n G$ serine/threonine protein kinase, Ppp protein phosphatase, Odh/ signal transduction protein, FHA-domain-containing protein, OdhA $\alpha$-oxoglutarate dehydrogenase, LpdA dihydrolipoamide dehydrogenase, SuCB dihydrolipoamide acetyltransferase. 
bio-safety, and robustness in fermentation $[19,20]$. In this work, C. crenatum argB-M4 $\triangle$ proB, whose $\operatorname{argR}$ was lethal via mutagenesis screening, pro $B$ gene was deleted, and $\arg B$ gene was replaced by $C$. crenatum $\arg B$ M4 gene (E19R, H26E, D311R, and D312R) to release L-Arg feedback inhibition, was chosen as a host strain to study L-Arg production. Furthermore, NCgl1221 (encoded as L-glutamate exporter) and $d t s R 1$ genes were knocked out using a marker-free system to increase L-Arg precursor. L-Arg production, ODHC specific activity, and NADPH pools accumulation by Tween 40 trigger and $d t s R 1$ gene regulation were explored, and the related genes transcription in response to inducing L-Arg production was investigated to elaborate the relationship among $d t s R 1$ gene deletion, Tween 40 addition, and L-Arg overproduction.

\section{Results and discussion}

\section{Effect of Tween 40 and DtsR1 on L-Arg production in C. crenatum}

Tween 40, as a fermentation trigger, can induce L-glutamate overproduction in C. glutamicum [21, 22]. To elaborate the effect of Tween 40 on L-Arg production in C. crenatum, we optimized Tween 40 addition and addition time in CCM01 strain. As shown in Fig. 2a, the biomass of $C$. crenatum gradually decreased with increasing concentration of Tween 40 from 0 to $8.0 \mathrm{mg} / \mathrm{mL}$, and the L-Arg production reached a maximum value when Tween 40 concentration was $5 \mathrm{mg} / \mathrm{mL}$ in the fermentation medium. The addition time of Tween 40 on L-Arg production is shown in Fig. $2 \mathrm{~b}$, indicating that $\mathrm{L}$-Arg overproduction could not be induced by Tween 40 addition before the $24 \mathrm{~h}$ fermentation time. During the logarithmic period (after $36 \mathrm{~h}$ fermentation time), Tween 40 addition significantly increased L-Arg production from
15.22 to $17.73 \mathrm{~g} / \mathrm{L}(P<0.05)$, while the yield of $\mathrm{L}-\mathrm{Arg}$ per gram biomass was increased from 1.54 to $2.24 \mathrm{~g} / \mathrm{g}$. Moreover, the yield of L-Arg per gram glucose increased from 0.22 to $0.30 \mathrm{~g} / \mathrm{g}$, consequently increasing $\mathrm{L}-\mathrm{Arg}$ productivity from 0.13 to $0.15 \mathrm{~g} / \mathrm{L} / \mathrm{h}$ in CCM01 strain (Table 1 ). The above results indicate that adding Tween 40 at the logarithmic period is conducive to L-Arg production. Meanwhile, the concentrations of other amino acids were analyzed using an amino acid analyzer. The results shown in Fig. 3 indicated that a large amount of L-glutamate was secreted into the fermentation supernatant $(4.72 \mathrm{~g} / \mathrm{L})$. To avoid L-glutamate leak during L-Arg fermentation, NCgl1221 gene encoding L-glutamate transporter $[23,24]$ was removed from the genome of CCM01 strain (named CCM02) to promote L-Arg production. As expected, extracellular L-glutamate in CCM02 strain decreased to an undetectable level (Fig. 3), whereas L-Arg production increased to $19.56 \mathrm{~g} / \mathrm{L}$ after Tween 40 trigger. Although Tween 40 addition increased L-Arg production in C. crenatum, the increased yield of L-Arg is very limited. A previous study has confirmed that disruption of $d t s R 1$ can convert the metabolic fluxes from tricarboxylic acid cycle toward glutamate synthesis by repressing ODHC specific activity [18]. To further improve L-Arg production, we knocked out the $d t s R 1$ gene in CCM02 strain (named CCM03). The results showed that extracellular L-Arg production in CCM03 strain drastically increased to $27.45 \mathrm{~g} / \mathrm{L}$, whereas L-lysine production evidently declined by $39.56 \%$ to $1.06 \mathrm{~g} / \mathrm{L}$ compared with $1.75 \mathrm{~g} / \mathrm{L}$ in CCM01 + Tween 40 condition (Fig. 3). The yield of L-Arg per gram glucose increased to $0.34 \mathrm{~g} / \mathrm{g}$, improving by $54.55 \%$ as compared with that in CCM01 strain (Table 1). Although L-Arg production after DtsR1 disruption is still low compared with the highest level

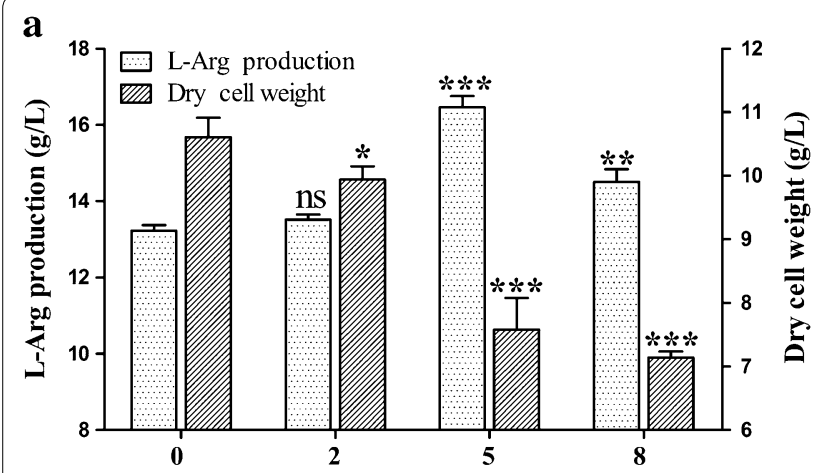

Tween 40 addition $(\mathrm{mg} / \mathrm{mL})$

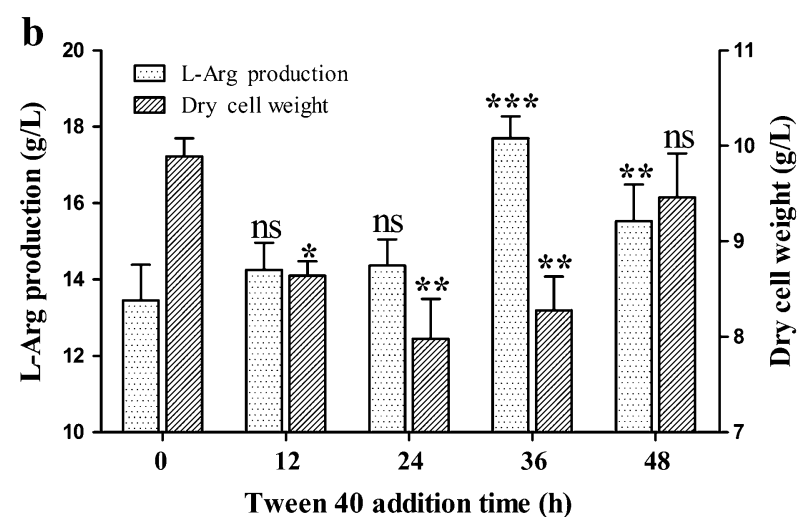

Tween 40 addition time (h)

Fig. 2 Effect of Tween 40 addition (0-8 mg/mL Tween 40, after $36 \mathrm{~h}$ incubation time) and addition time (0-48 h, $5 \mathrm{mg} / \mathrm{mL}$ Tween 40) on L-Arg production in CCM01 strain. L-Arg production and the DCW were monitored during shake flask cultivation for $120 \mathrm{~h}$ by Tween 40 addition. Results are the means \pm standard deviations from three independent experiments. Compared with the control group, "ns" designates $P>0.05,{ }^{*} P<0.05$; ${ }^{* *} P<0.01 ; * * * 0.001$. 
Table 1 Comparison of the performances of the different conditions for L-Arg production by fermentation

\begin{tabular}{|c|c|c|c|c|c|c|}
\hline \multirow[t]{2}{*}{ Conditions } & \multirow[t]{2}{*}{ GlcC (g/L) } & \multirow[t]{2}{*}{$\mathrm{DCW}(\mathrm{g} / \mathrm{L})$} & \multirow[t]{2}{*}{ Arginine (g/L) } & \multicolumn{2}{|l|}{ Yield } & \multirow[t]{2}{*}{$V_{p}(g / L / h)$} \\
\hline & & & & $\mathrm{Y}_{\mathrm{A} / \mathrm{G}}(\mathrm{g}$ arg/g glc) & $\mathrm{Y}_{\mathrm{A} / \mathrm{D}}(\mathrm{g} \arg / \mathrm{g} \mathrm{DCW})$ & \\
\hline CCM01 & $70.32 \pm 3.35$ & $9.92 \pm 0.35$ & $15.22 \pm 0.27$ & $0.22 \pm 0.01$ & $1.54 \pm 0.01$ & $0.13 \pm 0.03$ \\
\hline CCM01 + Tween 40 & $60.33 \pm 2.47$ & $7.91 \pm 0.42$ & $17.73 \pm 0.18$ & $0.30 \pm 0.02$ & $2.24 \pm 0.03$ & $0.15 \pm 0.04$ \\
\hline CCMO2 & $60.96 \pm 1.05$ & $8.34 \pm 1.07$ & $17.58 \pm 0.34$ & $0.29 \pm 0.04$ & $2.11 \pm 0.02$ & $0.15 \pm 0.04$ \\
\hline CCM02 + Tween 40 & $59.37 \pm 2.91$ & $7.36 \pm 0.27$ & $19.56 \pm 0.19$ & $0.33 \pm 0.03$ & $2.68 \pm 0.02$ & $0.16 \pm 0.02$ \\
\hline CCMO3 & $80.98 \pm 1.05$ & $8.17 \pm 1.07$ & $27.45 \pm 0.58$ & $0.34 \pm 0.05$ & $3.38 \pm 0.13$ & $0.23 \pm 0.02$ \\
\hline CCMO3 + Tween 40 & $89.34 \pm 3.91$ & $7.36 \pm 0.27$ & $29.97 \pm 1.13$ & $0.34 \pm 0.09$ & $4.10 \pm 0.15$ & $0.25 \pm 0.05$ \\
\hline
\end{tabular}

Fermentations were performed in a $250 \mathrm{~mL}$ flask at $30^{\circ} \mathrm{C}$; the initial glucose concentration was $120 \mathrm{~g} / \mathrm{L}$.

Results are the means \pm standard deviations in three independent experiments.

GlcC glucose consumed, $Y_{A / G}$ arginine yield vs. glucose, $Y_{A / D}$ arginine yield vs. DCW, $V_{P}$ volumetric productivity.

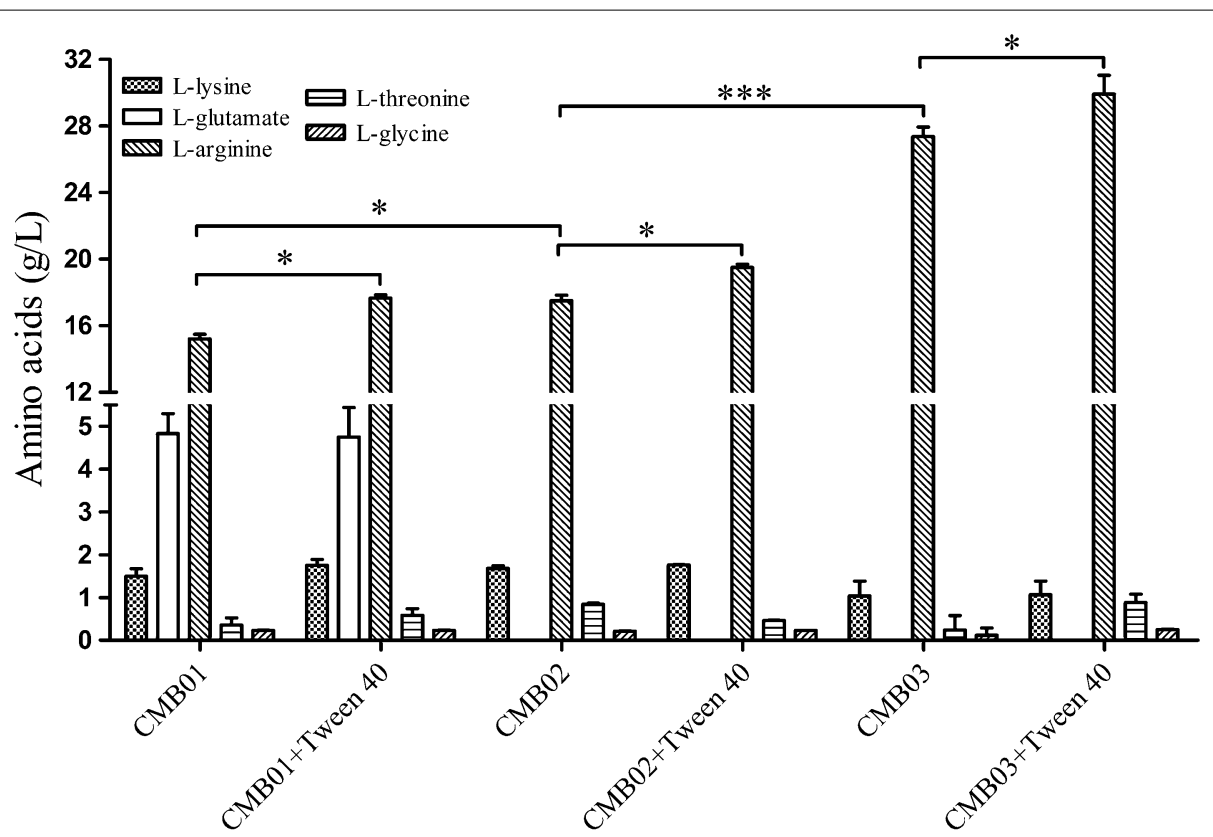

Fig. 3 Concentrations of various amino acids of different C. crenatum strains cultured at $30^{\circ} \mathrm{C}$ with Tween 40 addition in shake flask cultivation. Results are the means standard deviations from at least three independent experiments. ${ }^{*} P<0.05$; ${ }^{* * *} P<0.001$.

$(92.5 \mathrm{~g} / \mathrm{L})$ of that reported by Lee et al. $[14,15]$, it is notable that the yield of $\mathrm{L}$-Arg per gram glucose is basically consistent with the previous report, suggesting the CCM03 strain exhibits great potential to improve the yield of L-Arg by fed-batch fermentation. In addition, LArg production could further improve to approximately $9.12 \%(29.97 \mathrm{~g} / \mathrm{L})$ in CCM03 strain after Tween 40 addition. To further elaborate the function of Tween 40 and DtsR1 protein on L-Arg overproduction in C. crenatum, we investigated ODHC specific activity and NADPH pools accumulation.
Effect of Tween 40 and DtsR1 on ODHC specific activity and NADPH pools accumulation in C. crenatum

ODHC is a branch-point enzyme complex between the tricarboxylic acid cycle and L-glutamate biosynthesis. Tween 40 addition can indirectly convert the metabolic fluxes into the L-glutamate biosynthetic pathway by downregulating $d t s R 1$ gene expression; the disruption of $d t s R 1$ gene can reduce the ODHC activity, thereby inducing L-glutamate overproduction in C. glutamicum. In addition, L-glutamate production induced by Tween 40 addition can completely be suppressed by $d t s R 1$ gene 
disruption [25]. In the present study, ODHC specific activity decreased by 20.23 and $36.67 \%$ in CCM01 and CCM02 strains, respectively, during L-Arg fermentation after Tween 40 trigger (as shown in Fig. 4). When $d t s R 1$ gene was removed from the genome of C. crenatum (CCM03 strain), ODHC specific activity decreased to about $82.56 \%$ compared with that in CCM01 strain, and ODHC specific activity did not further decline after Tween 40 addition $(P>0.05)$, which was consistent with a previous report [25]. However, L-Arg production further increased in CCM03 + Tween 40 condition $(P<0.05$, Fig. 3$)$. The above results strongly suggest that probably other mechanisms exist for L-Arg overproduction induced by Tween 40 trigger after $d t s R 1$ disruption in C. crenatum.

A recent study has confirmed that NADPH pools accumulation is also conducive to $\mathrm{L}$-Arg production because the biosynthesis of $1 \mathrm{~mol}$ of L-Arg requires $3 \mathrm{~mol}$ of NADPH $[14,26]$. DtsR1 protein is one of the subunits of acetyl-CoA carboxylase complex, which is involved in fatty acid biosynthesis. Fatty acid biosynthesis requires a large amount of NADPH pools for fatty acid elongation cycle [27]. After DtsR1 disruption, the intracellular level of NADPH notably increased to $0.59 \mathrm{mmol} / \mathrm{L}$ in CCM03 strain, which was approximately three times higher than that of CCM01 strain (Table 2). The above results suggest that a large amount of NADPH pools for fatty acid biosynthesis was converted for L-Arg biosynthesis. We also

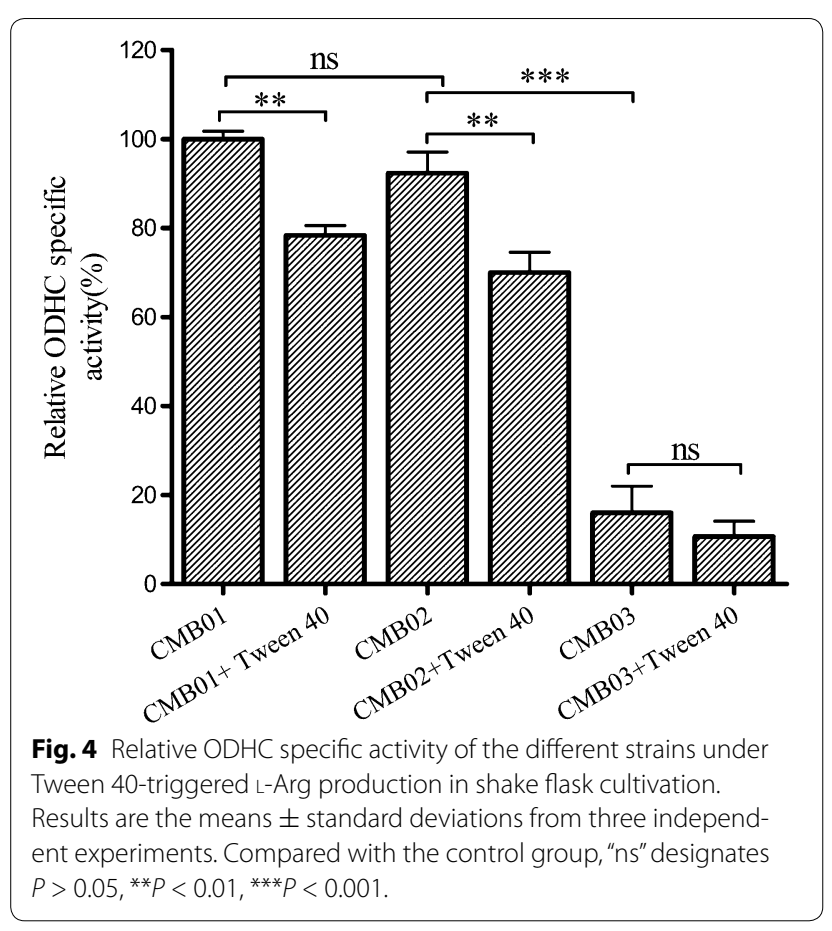

Table 2 Intracellular NADP+ and NADPH concentrations in different conditions

\begin{tabular}{llll}
\hline Conditions & $\begin{array}{l}\text { NADPH } \\
\text { (mmol/L) }\end{array}$ & $\begin{array}{l}\text { NADP }^{+} \\
(\mathbf{m m o l} / \mathbf{L})\end{array}$ & $\begin{array}{l}\text { NADP }^{+} \text {/ } \\
\text { NADPH }\end{array}$ \\
\hline CCM01 & $0.13 \pm 0.01$ & $0.25 \pm 0.02$ & 1.89 \\
CCM01 + Tween 40 & $0.30 \pm 0.04$ & $0.45 \pm 0.02$ & 1.49 \\
CCM02 & $0.15 \pm 0.03$ & $0.28 \pm 0.04$ & 1.90 \\
CCM02 + Tween 40 & $0.45 \pm 0.02$ & $0.68 \pm 0.05$ & 1.51 \\
CCM03 & $0.59 \pm 0.03$ & $0.78 \pm 0.01$ & 1.32 \\
CCM03 + Tween 40 & $0.75 \pm 0.18$ & $0.98 \pm 0.05$ & 1.31 \\
\hline
\end{tabular}

Results are the means \pm standard deviations in three independent experiments.

found that the NADPH level could further increase upon Tween 40 addition in CCM01, CCM02, and CCM03 strains. To date, relevant research about Tween 40 as a trigger for NADPH pools accumulation has not been reported.

\section{Regulation mechanism of Tween 40 and DtsR1 on L-Arg overproduction}

As shown in Fig. 4 and Table 2, L-Arg overproduction by Tween 40 trigger or DtsR1 disruption is attributed to reduced ODHC enzymatic activity and NADPH pools accumulation. ODHC complex consists of three subunits, including $\alpha$-oxoglutarate dehydrogenase encoded by odhA gene [28], dihydrolipoamide $S$-succinyltransferase encoded by $s u c B$ gene, and dihydrolipoamide dehydrogenase encoded by $l p d A$ gene [29]. A recent study has confirmed that ODHC activity regulation is not only related to the expression level of DtsR1 protein [17] but also with the phosphorylated and unphosphorylated forms of OdhI protein [30,31]. The downregulated expression of DtsR1 protein is in favor of reducing ODHC activity, and unphosphorylated OdhI is also as an inhibitor of ODHC because the FDH domain of unphosphorylated OdhI can combine with the OdhA subunit inhibiting ODHC activity [32]. OdhI protein can be phosphorylated by serine/ threonine protein kinases, including PknG and PknB, and dephosphorylated by phosphoserine/threonine protein phosphatase Ppp [33, 34]. In addition, intracellular $\mathrm{NADPH}$ is mainly generated from the pentose phosphate pathway, in which the gene cluster of $t k t-t a l-z w f-o p c A-$ $p g l$ is involved. Among them, glucose-6-phosphate dehydrogenase (encoded by $z w f$ gene) is responsible for regeneration of NADP ${ }^{+}$to NADPH [35]. To elucidate the regulation mechanism of Tween 40 and DtsR1 for L-Arg overproduction, we investigated the transcriptional levels of $d t s R 1, p p p, p k n G$, odhA, sucB, lpdA, $z w f$, and $\operatorname{argB}$, which is involved in the arginine biosynthetic pathway

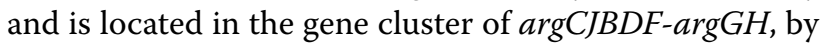
real-time quantitative PCR method. 
The results shown in Fig. 5 indicate that $d t s R 1$ and $p k n G$ were downregulated by 3.12- and 3.14-fold, respectively, whereas $p p p$ was upregulated by 2.80 -fold in CCM01/02 strain after Tween 40 trigger, and the transcriptional levels of $o d h A, \operatorname{sucB}$, and $\operatorname{lpd} A$ were concomitantly downregulated by 3.20-, 2.47-, and 2.19-fold, respectively, which were consistent with the previous report by Kataoka et al. [36]. We also found that the expression level of $\operatorname{argB}$ was upregulated by 17.25 -fold after removing the NCgl1221 gene in CCM02 strain. We suspected that the high expression of $\operatorname{argB}$ gene is associated with intracellular L-glutamate accumulation. After $d t s R 1$ disruption, the transcriptional level of $p k n G$ notably downregulated by 6.00-fold, and ppp transcription was upregulated by 8.53 -fold, which resulted in lesser transcriptional levels of $o d h A, s u c B$, and $l p d A$ in CCM03 strain compared with those in CCM01 strain. Meanwhile, the expression levels of $p k n G, p p p$, odhA, $s u c B$, and $l p d A$ remained unaltered in CCM03 strain after Tween 40 trigger. The above results demonstrated that reducing ODHC enzymatic activity induced by Tween 40 could be completely suppressed by $d t s R 1$ disruption in C. crenatum. We also found that $z w f$ transcription showed no significant difference among CCM01, CCM02, and CCM03 strains $(P>0.05)$. The above results indicated that $N C g l 1221$ and $d t s R 1$ expression were not associated with $\mathrm{NADP}^{+} / \mathrm{NADPH}$ regeneration, and the increase in intracellular NADPH level after DtsR1 deletion could come from fatty acid synthesis. However, after adding Tween 40 , the transcriptional level of $z w f$ gene increased by 5.50 fold in CCM01, CCM02, and CCM03 strains. This result suggests that Tween 40 could be a key trigger in inducing NADPH regeneration for $\mathrm{L}$-Arg overproduction.

\section{Conclusion}

A novel strategy for overproducing L-Arg by reduction of ODHC enzymatic activity and promotion of NADPH accumulation in $C$. crenatum was reported. To avoid intracellular L-glutamate secretion and reduce ODHC specific activity, we successfully deleted NCgl1221 and $d t s R 1$ by using a marker-free system in C. crenatum. LArg production significantly increased from 15.22 to $27.45 \mathrm{~g} / \mathrm{L}$, and L-Arg production further enhanced by $29.97 \mathrm{~g} / \mathrm{L}$ after Tween 40 trigger. We also, for the first time, found that Tween 40 addition not only downregulated $d t s R 1$ expression but also induced $\mathrm{NADP}^{+} /$ $\mathrm{NADPH}$ regeneration by upregulating $z w f$ expression. However, further experiments, such as transcriptomics,

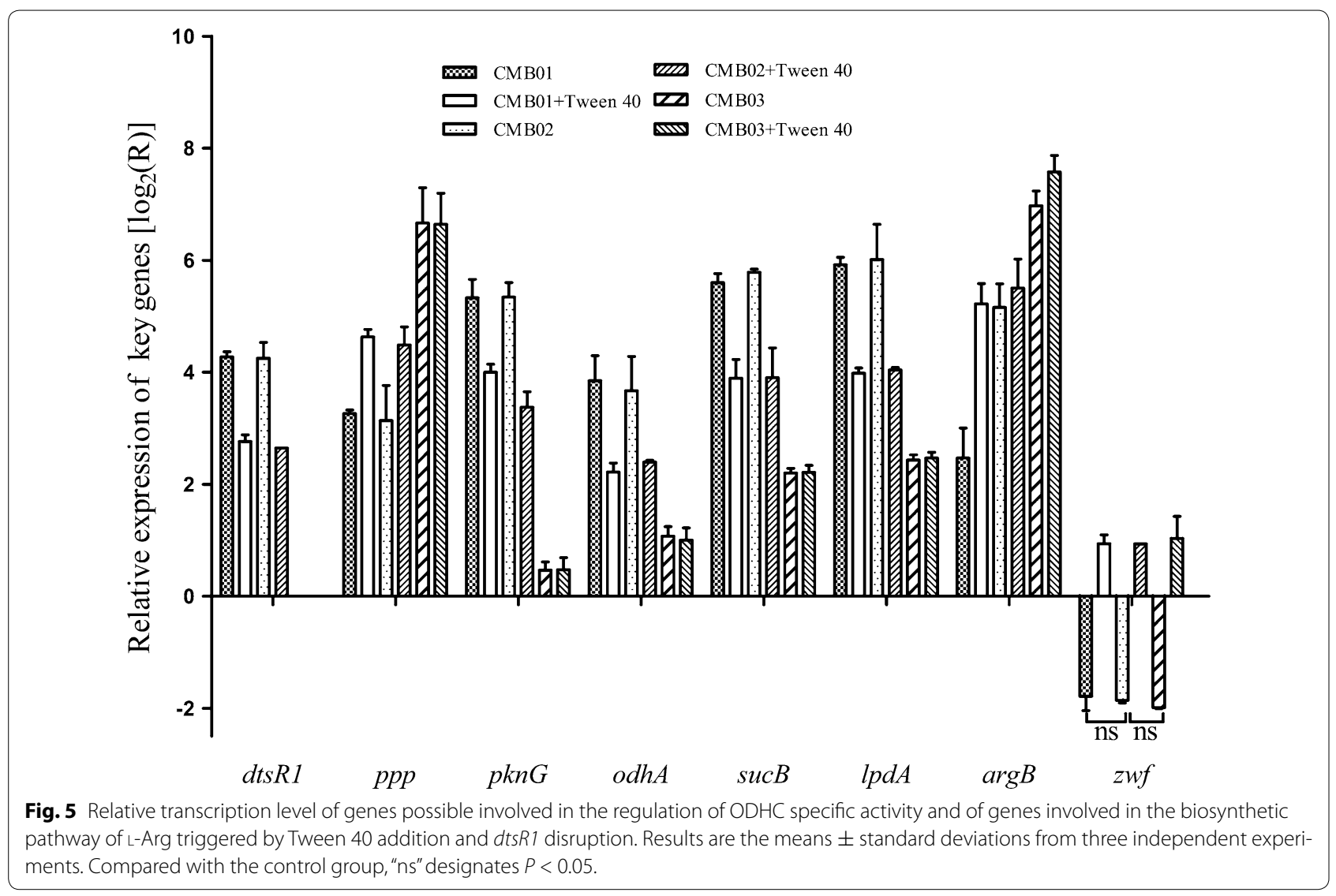


proteomics, and metabolic engineering, are necessary to elucidate the more detailed mechanism of L-Arg overproduction by Tween 40 trigger.

\section{Methods}

Strains, plasmids and primers

Corynebacterium crenatum argB-M4 $\triangle$ proB strain (named CCM01) used as a parent strain in this study was constructed in our previous work (data not shown), whose $\operatorname{argR}$ was lethal via mutagenesis screening, the pro $B$ gene was knocked out, and $\arg B$ was replaced by $\operatorname{argB}$ M4 (E19R, H26E, D311R, and D312R) to release LArg feedback resistance. The strains and plasmids used in this study are listed in Table 3. The primers used for strain construction and RT-quantitative (q) PCR amplification are listed in Table 4.

\section{Strain construction}

Escherichia coli $\mathrm{DH} 5 \alpha$ strain was used as a primary host for all gene cloning. Corynebacterium crenatum was grown in Luria-Bertani (LB) medium at $210 \mathrm{rpm}$ and $30{ }^{\circ} \mathrm{C}$, while $E$. coli was grown in LB medium at $180 \mathrm{rpm}$ and $37{ }^{\circ} \mathrm{C}$. Unless otherwise indicated, the concentration of Kanamycin was $25 \mu \mathrm{g} / \mathrm{mL}$. CCM01 with deleted NCgl1221 gene (named CCM02) was obtained by knocking out NCgl1221 gene by using a marker-free system with Bacillus subtilis $s a c B$ gene via two rounds of recombination as described previously [37]. The fusion arms containing $5^{\prime}$-upstream and $3^{\prime}$-downstream fragments were obtained by overlapping PCR. These fusion arms were then used for construction of recombinant plasmid by inserting them into the $\mathrm{pK} 18 \mathrm{mobsacB}$ vector. The resultant recombinant plasmid was transferred into $C$. crenatum by electroporation. The single crossover strains were selected on LBHIS (LB supplemented with brain heart infusion and sorbitol) agar plates containing $10 \mu \mathrm{g} /$ $\mathrm{mL}$ kanamycin, whereas marker-free recombinants were screened on sucrose-resistant agar plates. Moreover, CCM02 with deleted $d t s R 1$ gene (named CCM03) underwent the same procedure as the previous strains.

\section{L-Arg fermentation}

The seed medium for $C$. crenatum cultivation (per liter) consisted of $30 \mathrm{~g}$ of glucose, $20 \mathrm{~g}$ of corn steep liquor, $20 \mathrm{~g}$ of $\left(\mathrm{NH}_{4}\right)_{2} \mathrm{SO}_{4}, 1 \mathrm{~g}$ of $\mathrm{KH}_{2} \mathrm{PO}_{4}, 0.5 \mathrm{~g}$ of $\mathrm{MgSO}_{4} \cdot 7 \mathrm{H}_{2} \mathrm{O}$, and $1.5 \mathrm{~g}$ of urea. For seed culture, cells on the LB medium plate were inoculated into a test tube containing $5 \mathrm{~mL}$ of the LB medium, and cultivated in a shaking incubator with $210 \mathrm{rpm}$ at $30{ }^{\circ} \mathrm{C}$ for $24 \mathrm{~h}$. One milliliter of the culture was transferred to a $250 \mathrm{~mL}$ flask containing $30 \mathrm{~mL}$ of the seed medium. After the optical density of seed culture $\left(\mathrm{OD}_{562}\right)$ was reached between 5.5 and 6.0, $2.0 \mathrm{~mL}$ seed culture was transferred into a $250 \mathrm{~mL}$ flask containing $25 \mathrm{~mL}$ the fermentation medium and cultured at $30{ }^{\circ} \mathrm{C}$ for $120 \mathrm{~h}$. The fermentation medium (per liter) for L-Arg production was composed of $120 \mathrm{~g}$ of glucose, $25 \mathrm{~g}$ of corn steep liquor, $45 \mathrm{~g}$ of $\left(\mathrm{NH}_{4}\right)_{2} \mathrm{SO}_{4}, 1 \mathrm{~g}$ of $\mathrm{KH}_{2} \mathrm{PO}_{4}, 0.5 \mathrm{~g}$ of $\mathrm{MgSO}_{4} \cdot 7 \mathrm{H}_{2} \mathrm{O}$, and $30 \mathrm{~g}$ of $\mathrm{CaCO}_{3}(\mathrm{pH}$ 7.0). D-Biotin was supplied from the corn steep liquor of the medium [20]. For the growth of CCM03 strain ( $\Delta$ proB $\Delta N C g l 1221 \Delta d t s R 1)$, L-proline and oleic acid ester (Tween 80) were added to media with final concentrations of 2.5 and $1 \mathrm{mg} / \mathrm{mL}$, respectively. Tween 40 was added to the medium to a final concentration of $5 \mathrm{mg} / \mathrm{mL}$ once cell growth reached the early exponential phase to further trigger L-Arg overproduction. Cell concentration was determined at $562 \mathrm{~nm}$ and measured by a pre-calibrated relationship $(1 \mathrm{OD}=0.375 \mathrm{~g} / \mathrm{L})$. 3,5-Dinitrosalicylic acid colorimetry was used to measure glucose concentration in the culture [38]. Concentrations of L-Arg and other amino acids were determined using a Sykam S-433D amino acid analyzer (Sykam Co. Ltd., Germany). All the data are presented as means \pm standard deviations in three independent experiments.

Table 3 Strains and plasmids used in this study

\begin{tabular}{|c|c|c|}
\hline Strains/plasmids & Function and relevant characteristics & Sources \\
\hline \multicolumn{3}{|l|}{ Strains } \\
\hline $\mathrm{DH} 5 \alpha$ & General clone host strain & Invitrogen \\
\hline C. crenatum MT & Mutation strain with auxotrophic for biotin, and producing L-Arg & Lab stock \\
\hline CCM01 & $\begin{array}{l}\text { C. crenatum MT with proB gene deletion, which E-argB gene replaced by C. crenatum argB } \\
\text { M4 gene (E19R, H26E, D311R, and D312R) }\end{array}$ & This work \\
\hline CCMO2 & Chromosomal deletion of the Ncgl1221 gene of CCM01 & This work \\
\hline CCMO3 & Chromosomal deletion of the $d t s R 1$ gene of CCM02 & This work \\
\hline \multicolumn{3}{|l|}{ Plasmids } \\
\hline pK18mobsacB & Mobilizable vector, allows for selection of double crossover in C. crenatum, $\mathrm{Km}^{\mathrm{R}}$, sacB & Lab stock \\
\hline pK18- $\Delta$ NCg/1221 & A derivative of pK18mobsacB, harboring $\Delta$ NCg/1221 fragment & This work \\
\hline $\mathrm{pK} 18-\Delta d t s R 1$ & A derivative of pK18mobsacB, harboring $\Delta d t s R 1$ fragment & This work \\
\hline
\end{tabular}


Table 4 Sequences of oligonucleotide primers

\begin{tabular}{|c|c|c|}
\hline Primers & Sequence $\left(5^{\prime}-3^{\prime}\right)$ & Purposes \\
\hline NCg/1221-up-F & CGCAAGCTTCAAGAAAGCCCTCGTTCCAACACTG & Amplifying the left arm of NCg/1221 \\
\hline NCg/1221-up-R & ATCAGCGTCCTAAGGAATCAAAAACGCCAAGACCAGG & \\
\hline NCgl1221-down-F & GGCGTTTTTGATTCCCTTAGGACGCTGATTACAGACG & Amplifying the right arm of $\mathrm{NCg} / 1221$ \\
\hline NCgl1221-down-R & GCATCTAGAGGAAGGGAGTTGAAGGTGACG & \\
\hline dtsR1-up-F & CGCAAGCTTCAGCAAGTCAGCATTAGTGGAGC & Amplifying the left arm of $d t s R 1$ \\
\hline$d t s R 1-u p-R$ & GCCGATTTACAGTGTGAAATCGTAGCGGTAGG & \\
\hline dtsR1-down-F & CCGCTACGATTTCACACTGTAAATCGGCGAATCC & Amplifying the right arm of $d t s R 1$ \\
\hline dtsR1-down-R & GCATCTAGAGGAAGGGAGTTGAAGGTGACG & \\
\hline odhA-F & TCATTGAGGCATACCGCTCC & RP of odhA \\
\hline odhA-R & TGAAGGTACGGTCCAGATCC & \\
\hline$I p d A-F$ & TGGGACTTAACCGTGGGCT & $\mathrm{RP}$ of $I p d A$ \\
\hline$I p d A-\mathrm{R}$ & CACACCGTTAATCATGCGGAC & \\
\hline sucB-F & TCGTGAAGCGTCCAGTTGTC & $\mathrm{RP}$ of $s u C B$ \\
\hline$s u c B-R$ & GGTCCTTGATGGTGGTCAGG & \\
\hline$p k n G-F$ & GGCGGCATGGGTTGGATTT & RP of $p k n G$ \\
\hline$p k n G-R$ & GTGCCTTGGTCTTGAACGGA & \\
\hline$p p p-F$ & CGGTATTGATCGTAGCCCTG & $\mathrm{RP}$ of $p p p$ \\
\hline$p p p-\mathrm{R}$ & CGCGACGTAAAAAGTGCTG & \\
\hline$d t s R 1-\mathrm{F}$ & СCTCCCATCCAACAATCGCT & $\mathrm{RP}$ of $d t s R 1$ \\
\hline$d t s R 1-R$ & TAAGGAACGGTCGCGGAATC & \\
\hline$z w f-F$ & ACTGAGATTGCCGTGGTGTT & RP of $z w f$ \\
\hline$z W f-R$ & AGCGGATGAGCACACCTTC & \\
\hline $\arg B-F$ & GTCGCGATTTAGTTGGTTTGAT & $\mathrm{RP}$ of $\arg B$ \\
\hline $\arg B-R$ & GAGGCATCGACATTAATGATGTCT & \\
\hline 16s rRNA-F & AAGAAGCACCGGCTAACTAC & Reference Gene \\
\hline 16s rRNA-R & CCGGGATTTCACAGACGAC & \\
\hline
\end{tabular}

Restriction sites were highlighted in bold; linker sequences for crossover PCR were shown in underline. RP RT-qPCR.

\section{Measurement of ODHC specific activity and concentrations} of intracellular NADP ${ }^{+}$and NADPH pools

Samples preparation and ODHC specific activity were conducted according to a previously described method $[39,40]$. According to the previous work, the L-Arg production rate was kept highest during 36-60 h fermentation time (data not show), therefore, C. crenatum cells were harvested in the late exponential phase (after $48 \mathrm{~h}$ cultivation), and collected by centrifugation at 5,000 rpm at $4{ }^{\circ} \mathrm{C}$ for $10 \mathrm{~min}$. The pellets were diluted with $0.2 \mathrm{M}$ $\mathrm{HCl}$ to dissolve $\mathrm{CaCO}_{3}$ and then washed twice with $0.2 \%$ $\mathrm{KCl}$ solution. The pure cells were suspended in $5 \mathrm{~mL}$ of $0.1 \mathrm{M} N$-tris(hydroxymethyl)methyl-2-aminoethanesulfonic acid (TES) $\mathrm{NaOH}$ buffer ( $\mathrm{pH} 7.7)$ containing $30 \%$ (v/v) glycerol and $10 \mathrm{mg} / \mathrm{mL}$ lysozyme. Following incubation at $37{ }^{\circ} \mathrm{C}$ for $3 \mathrm{~h}$, the cells were disrupted by sonication and centrifuged to remove cell debris. The supernatant was collected, and the protein concentration was determined by Nanodrop 2000 (Thermo Scientific, Germany).
ODHC specific activity assay was performed by adding $100 \mu \mathrm{L}$ of cell extract to $2.5 \mathrm{~mL}$ of reaction mixture. The reaction mixture contained $100 \mathrm{mM}$ TES. $\mathrm{NaOH}$ buffer (pH 7.7), $5 \mathrm{mM} \mathrm{MgCl}_{2}, 3 \mathrm{mM}$ cysteine, $0.3 \mathrm{mM}$ thiamine pyrophosphate, $0.2 \mathrm{mM}$ coenzyme $\mathrm{A}$, and $1 \mathrm{mM}$ 3 -acetylpyridine adenine dinucleotide $\left(\mathrm{APAD}^{+}\right)$. Upon adding $1 \mathrm{mM} \alpha$-oxoglutarate to the reaction mixture, the initial increase in the absorbance of APADH at $365 \mathrm{~nm}$ was consecutively measured at $31.5{ }^{\circ} \mathrm{C}$ for $5 \mathrm{~min}$ with $30 \mathrm{~s}$ intervals. ODHC specific activity is defined as the amount of enzyme required to generate $1 \mu \mathrm{mol} \mathrm{NADH}$ per minute. The molar extinction coefficient of $\mathrm{NAD}^{+}$ was 9.1.

Intracellular $\mathrm{NADP}^{+}$and NADPH concentrations were determined by enzymatic cycling reaction initiated with the EnzyChrom ${ }^{\mathrm{TM}} \mathrm{NADP}^{+} / \mathrm{NADPH}$ Assay kit (BioAssay Systems, Hayward, CA 94545, USA). All the data are presented as the means \pm standard deviations in three independent experiments. 


\section{Real-time fluorescence reverse transcription quantitative PCR}

The total RNA from CCM01, CCM01 + Tween 40, CCM 02, CCM02 + Tween 40, CCM03, and CCM03 + Tween 40 conditions after $48 \mathrm{~h}$ fermentation was extracted using a Trizol Plus RNA Purification Kit according to the manufacturer's instructions (Invitrogen ${ }^{\mathrm{TM}}$, USA). cDNA was synthesized by the Primer Script ${ }^{\mathrm{TM}}$ RT Reagent Kit with gDNA Eraser (TaKaRa, Japan). The transcription levels of the $\arg B, z w f$, odhA, $\operatorname{lpd} A, s u c B, d t s R 1$, $p k n G$, and $p p p$ genes were analyzed by the real-time fluorescence reverse transcription quantitative PCR (RTqPCR) using SYBR ${ }^{\circledR}$ Premix Tag $^{\text {TM }}$ (Tli RNaseH Plus) Kit (TaKaRa, Japan) with the corresponding primers (listed in Table 4). $16 \mathrm{~S}$ rRNA was adopted as a reference gene. The thermal cycling conditions were $95{ }^{\circ} \mathrm{C}$ for $30 \mathrm{~s}$, followed by 40 cycles of $95{ }^{\circ} \mathrm{C}$ for $5 \mathrm{~s}$ and $60{ }^{\circ} \mathrm{C}$ for $30 \mathrm{~s}$. A control reaction without template was implemented to evaluate primer dimmer formation. The relative transcription level for each gene was calculated through the $2^{-\Delta \Delta C_{t}}$ method [41]. All the data are presented as the means \pm standard deviations in three independent experiments.

\section{Statistical analysis}

The data were statistically compared using ANOVA, and significant differences were identified by Tukey- $t$ test $(P<0.05)$. These analyses were carried out in GraphPad Prism 5.0 software (GraphPad software Inc, California, USA).

\section{Authors' contributions}

$\mathrm{XYH}$ and $\mathrm{CXL}$ conceived the study, participated in its design and coordination. CML designed and carried out the molecular genetic work, performed the analysis, and drafted the manuscript. WF carried out the fermentation studies, ZB and CJC analyzed the data. All authors read and approved the final manuscript.

\section{Author details \\ ${ }^{1}$ College of Life Science, Nanchang University, Nanchang 330031, People's Republic of China. ${ }^{2}$ Key Laboratory of Functional Small Organic Molecule, Ministry of Education, Jiangxi Normal University, 99 Ziyang Road, Nan- chang 330022, People's Republic of China. ${ }^{3}$ State Key Laboratory of Food Science and Technology, Jiangxi-OAI Joint Research Institute, Nanchang Uni- versity, 235 Nanjing East Road, Nanchang 330047, People's Republic of China.}

\section{Acknowledgements}

This work was supported by the Natural Science Foundation of China (No. 31360219 and No. 30960012).

\section{Compliance with ethical guidelines}

\section{Competing interests}

The authors declare that they have no competing interests.

Received: 22 May 2015 Accepted: 4 August 2015

Published online: 12 August 2015

\section{References}

1. Alba-Roth J, MÜller OA, Schopohl J, Werder KV (1988) Arginine stimulates growth hormone secretion by suppressing endogenous somatostatin secretion. J Clin Endocrinol Metab 67:1186-1189

2. Thams P, Capito K (1999) L-Arginine stimulation of glucose-induced insulin secretion through membrane depolarization and independent of nitric oxide. Eur J Endocrinol 140:87-93

3. Davis S (1972) Plasma levels of prolactin, growth hormone, and insulin in sheep following the infusion of arginine, leucine and phenylalanine. Endocrinology 91:549-555

4. Bronte V, Zanovello P (2005) Regulation of immune responses by L-arginine metabolism. Nat Rev Immunol 5:641-654

5. Ignarro LJ, Cirino G, Casini A, Napoli C (1999) Nitric oxide as a signaling molecule in the vascular system: an overview. J Cardiovasc Pharmacol 34:879-886

6. Nakayama K, Yoshida H (1972) Fermentative production of L-arginine. Agric Biol Chem 36:1675-1684

7. Rahman MM, Qin ZQ, Dou W, Zhiming R, Xu Z (2013) Over-expression of NAD kinase in Corynebacterium crenatum and its impact on L-arginine biosynthesis. Trop J Pharm Res 11:909-916

8. Ginesy M, Belotserkovsky J, Enman J, Isaksson L, Rova U (2015) Metabolic engineering of Escherichia coli for enhanced arginine biosynthesis. Microb Cell Fact 14:29

9. Kisumi M, Kato J, Sugiura M, Chibata I (1971) Production of L-arginine by arginine hydroxamate-resistant mutants of Bacillus subtilis. Appl Microbiol 22:987-991

10. Yoshida H, Araki K, Nakayama K (1981) L-arginine production by arginine analog-resistant mutants of microorganisms. Agric Biol Chem 45:959-963

11. Xu M, Rao Z, Dou W, Yang J, Jin J, Xu Z (2012) Site-directed mutagenesis and feedback-resistant $N$-acetyl-L-glutamate kinase (NAGK) increase Corynebacterium crenatum L-arginine production. Amino Acids 43:255-266

12. Xu M, Rao Z, Yang J, Xia H, Dou W, Jin J et al (2012) Heterologous and homologous expression of the arginine biosynthetic $\arg \mathrm{C} \sim \mathrm{H}$ cluster from Corynebacterium crenatum for improvement of L-arginine production. J Ind Microbiol Biotechnol 39(3):495-502

13. Xu M, Rao Z, Yang J, Dou W, Xu Z (2013) The effect of a LYSE exporter overexpression on L-arginine production in Corynebacterium crenatum. Curr Microbiol 67(3):271-278

14. Park SH, Kim HU, Kim TY, Park JS, Kim S-S, Lee SY (2014) Metabolic engineering of Corynebacterium glutamicum for L-arginine production. Nat Commum 5:4618

15. Shin JH, Lee SY (2014) Metabolic engineering of microorganisms for the production of L-arginine and its derivatives. Microb Cell Fact 13:66

16. Kimura E, Yagoshi C, Kawahara Y, Ohsumi T, Nakamatsu T, Tokuda H (1999) Glutamate overproduction in Corynebacterium glutamicum triggered by a decrease in the level of a complex comprising DtsR and a biotin-containing subunit. Biosci Biotechnol Biochem 63(7):1274-1278

17. Kimura $E$ (2002) Triggering mechanism of $L$-glutamate overproduction by DtsR1 in coryneform bacteria. J Biosci Bioeng 94(6):545-551

18. Yao W, Deng X, Zhong H, Liu M, Zheng P, Sun Z et al (2009) Double deletion of $d t s R 1$ and pyc induce efficient L-glutamate overproduction in Corynebacterium glutamicum. J Ind Microbiol Biotechnol 36(7):911-921

19. Xu H, Dou W, Xu H, Zhang X, Rao Z, Shi Z et al (2009) A two-stage oxygen supply strategy for enhanced L-arginine production by Corynebacterium crenatum based on metabolic fluxes analysis. Biochem Eng J 43(1):41-51

20. Dou W, Xu M, Cai D, Zhang X, Rao Z, Xu Z (2011) Improvement of L-arginine production by overexpression of a bifunctional ornithine acetyltransferase in Corynebacterium crenatum. Appl Biochem Biotechnol 165(34):845-855

21. Shimizu H, Tanaka H, Nakato A, Nagahisa K, Kimura E, Shioya S (2003) Effects of the changes in enzyme activities on metabolic flux redistribution around the 2-oxoglutarate branch in glutamate production by Corynebacterium glutamicum. Bioprocess Biosyst Eng 25(5):291-298

22. Asakura Y, Kimura E, Usuda Y, Kawahara Y, Matsui K, Osumi T et al (2007) Altered metabolic flux due to deletion of odhA causes L-glutamate overproduction in Corynebacterium glutamicum. Appl Environ Microbiol 73(4):1308-1319 
23. Nakamura J, Hirano S, Ito H, Wachi M (2007) Mutations of the Corynebac terium glutamicum NCg/1221 gene, encoding a mechanosensitive channel homolog, induce L-glutamic acid production. Appl Environ Microbiol 73:4491-4498

24. Hashimoto K, Nakamura K, Kuroda T, Yabe I, Nakamatsu T, Kawasaki H (2010) The protein encoded by NCg/1221 in Corynebacterium glutamicum functions as a mechanosensitive channel. Biosci Biotechnol Biochem 74(12):2546-2549

25. Kimura E, Abe C, Kawahara Y, Nakamatsu T, Tokuda H (1997) A dtsR genedisrupted mutant of Brevibacterium lactofermentum requires fatty acids for growth and efficiently produces L-glutamate in the presence of an excess of biotin. Biochem Bioph Res Commun 234(1):157-161

26. Takeno S, Murata R, Kobayashi R, Mitsuhashi S, Ikeda M (2010) Engineering of Corynebacterium glutamicum with an NADPH-generating glycolytic pathway for L-lysine production. Appl Environ Microbiol 76:7154-7160

27. Lennen RM, Pfleger BF (2012) Engineering Escherichia coli to synthesize free fatty acids. Trends Biotechnol 30(12):659-667

28. Usuda Y, Tujimoto N, Abe C, Asakura Y, Kimura E, Kawahara Y et al (1996) Molecular cloning of the Corynebacterium glutamicum ('Brevibacterium lactofermentum'AJ12036) odhA gene encoding a novel type of 2-oxoglutarate dehydrogenase. Microbiology 142:3347-3354

29. Schwinde JW, Hertz PF, Sahm H, Eikmanns BJ, Guyonvarch A (2001) Lipoamide dehydrogenase from Corynebacterium glutamicum: molecular and physiological analysis of the Ipd gene and characterization of the enzyme. Microbiology 147:2223-2231

30. Krawczyk S, Raasch K, Schultz C, Hoffelder M, Eggeling L, Bott M (2010) The FHA domain of Odhl interacts with the carboxyterminal 2-oxoglutarate dehydrogenase domain of OdhA in Corynebacterium glutamicum. FEBS Lett 584:1463-1468

31. Raasch K, Bocola M, Labahn J, Leitner A, Eggeling L, Bott M (2014) Interaction of 2-oxoglutarate dehydrogenase OdhA with its inhibitor Odhl in Corynebacterium glutamicum: mutants and a model. J Biotechnol 191:99-105

32. Niebisch A, Kabus A, Schultz C, Weil B, Bott M (2006) Corynebacterial protein kinase $\mathrm{G}$ controls 2-oxoglutarate dehydrogenase activity via the phosphorylation status of the Odhl protein. J Biol Chem 281(18):12300-12307
33. Schultz C, Niebisch A, Schwaiger A, Viets U, Metzger S, Bramkamp M et al (2009) Genetic and biochemical analysis of the serine/threonine protein kinases PknA, PknB, PknG and PknL of Corynebacterium glutamicum: evidence for non-essentiality and for phosphorylation of Odhl and FtsZ by multiple kinases. Mol Microbiol 74(3):724-741

34. Schultz C, Niebisch A, Gebel L, Bott M (2007) Glutamate production by Corynebacterium glutamicum: dependence on the oxoglutarate dehydrogenase inhibitor protein Odhl and protein kinase PknG. Appl Microbiol Biotechnol 76(3):691-700

35. Liu Z, Chen L, Hao N, Xu L, Li Y, Yan M et al (2015) Expression of glucose6-phosphate dehydrogenase and 6-phosphogluconate dehydrogenase improve L-citrulline biosynthesis in argG-deleted Corynebacterium glutamicum. In: Advances in applied biotechnology, vol 333. Springer, Berlin, pp 197-204

36. Kataoka M, Hashimoto Kl, Yoshida M, Nakamatsu T, Horinouchi S, Kawasaki H (2006) Gene expression of Corynebacterium glutamicum in response to the conditions inducing glutamate overproduction. Lett Appl Microbiol 42(5):471-476

37. Xu J, Xia X, Zhang J, Guo Y, Qian H, Zhang W (2014) A method for gene amplification and simultaneous deletion in Corynebacterium glutamicum genome without any genetic markers. Plasmid 72:9-17

38. Miller GL (1959) Use of dinitrosalicylic acid reagent for determination of reducing sugar. Anal Chem 31:426-428

39. Shiio I, Ujigawa-Takeda K (1980) Presence and regulation of $\alpha$-ketoglutarate dehydrogenase complex in a glutamate-producing bacterium, Brevibacterium flavum. Agric Biol Chem 44(8):1897-1904

40. Kim J, Hirasawa T, Sato Y, Nagahisa K, Furusawa C, Shimizu H (2009) Effect of odhA overexpression and odhA antisense RNA expression on Tween40-triggered glutamate production by Corynebacterium glutamicum Appl Microbiol Biotechnol 81(6):1097-1106

41. Livak KJ, Schmittgen TD (2001) Analysis of relative gene expression data using real-time quantitative PCR and the 2(-Delta Delta C (T)). Methods 25:402-408

\section{Submit your next manuscript to BioMed Central and take full advantage of:}

- Convenient online submission

- Thorough peer review

- No space constraints or color figure charges

- Immediate publication on acceptance

- Inclusion in PubMed, CAS, Scopus and Google Scholar

- Research which is freely available for redistribution

Submit your manuscript at

www.biomedcentral.com/submit

C BioMed Central 